\title{
Human rights and civil liberties
}

A foundational principle of liberal democracy is that all citizens are equal, and so the protection of fundamental human rights is of critical importance for democratic effectiveness. In many countries a statement of citizens' rights forms part of the constitution, and is especially enshrined in law and enforced by the courts. This has not happened in the UK, which has no codified constitution. Instead Colm O'Cinneide evaluates the more diffuse and eclectic ways in which the UK's political system protects fundamental human rights through the Human Rights Act and other legislation, and the courts and Parliament.

\section{How must human rights and civil liberties be protected in a democracy?}

Liberal democratic states are now expected to respect a range of fundamental human rights set out in international human rights treaties such as the European Convention on Human Rights ('the Convention'). These extend from freedom from torture, to the right to fair trial and freedom from discrimination.

It is generally recognised that the functioning of any genuine democracy must be based on respect for these rights, without which individuals cannot participate freely or effectively in the political process.

In the UK constitutional system it is generally assumed that the political branches of government should play a leading role in resolving disputes about the scope and substance of individual rights. However, the courts have become increasingly involved in adjudicating human rights issues over the last few decades. The protection of individual rights is now usually viewed as forming part of the 'mission statement' of the judicial branch of government, and human rights cases now form a considerable element of the case-load of the UK's superior courts.

\section{The Human Rights Act}

The Human Rights Act ('the HRA'), passed in 1998 by the first Blair government, is central to the current system of rights protection. It avoided the knotty problem of specifying a list of 
particularly 'British' rights by imposing a duty on all public authorities (aside from Parliament itself) to act compatibly with the rights covered in the European Convention of Human Rights (hereafter 'the Convention'), to which the UK has been a signatory since 1951. The Act also gave the UK courts the power to overturn decisions by UK public authorities which breached Convention rights, but not to overrule legislation passed by Parliament. The courts were given the power to declare such legislation to be 'incompatible' with the Convention, and to interpret it where possible in a Convention-friendly manner. However, the ultimate decision whether or not to change legislation that has a negative impact on Convention rights was left in the hands of Parliament - which therefore retains the final say as to what constitutes British law.

If an individual fails to get a remedy before the UK courts under the HRA, they can take a case to the European Court of Human Rights in Strasbourg, as happened over voting rights for prisoners in UK jails. Any judgments made by the European Court of Human Rights against the UK are not binding upon UK public authorities or Parliament. However, strong expectations exist that such judgments by the Strasbourg Court will be complied with by the UK, along with all the states in the Council of Europe.

In addition to the HRA, the common law and other statutes passed by Parliament also play an important role in protecting individual rights by imposing important legal constraints upon public authorities. For example, the Equality Act 2010 prevents public authorities discriminating on the basis of race, sex, disability and other grounds of equal treatment. However, these extra sources of legal rights protection play supporting roles when compared to the HRA.

Despite these various layers of legal protection, human rights nevertheless remain a contested concept in the British political tradition. They are capable of being interpreted and understood in different ways. Deep disagreement often exists as to what exactly constitutes a breach of a fundamental right. Furthermore, different views exist as to when and how the courts should intervene to protect individual rights. Politicians regularly subject the HRA to criticism, and bemoan the influence exerted by the jurisprudence of the European Court of Human Rights (ECHR) over UK law. In 2010 and again in 2015 the Conservative election manifesto proposed replacing the HRA with a 'British Bill of Rights', although in practice Tory governments since 2015 have not been able to implement this idea.

Successive UK governments have also introduced legislation that has diluted protections for civil liberties and fundamental rights in the spheres of national security/counterterrorism, immigration and socio-economic entitlements: it is likely that this pattern will continue. Brexit is posing further challenges, by in particular removing the safety blanket for certain non-discrimination, migrant and labour rights formerly provided by EU law.

The place of both the HRA and European Convention of Human Rights within the UK's legal system thus remains open to debate, as does the status of human rights values more generally: no consensus yet exists as to how human rights should best be protected within the framework of the British constitution. And while the scope of legal rights protection in the UK is relatively strong, it is limited. Socio-economic rights are particularly poorly covered, and international human rights law has very limited impact on UK law or policy. 


\section{Strengths, Weaknesses, Opportunities, Threats (SWOT) analysis}

\section{Current strengths}

The UK's constitutional culture values civil liberties (at least in the abstract). There is a formal embrace of human rights values within government. Plenty of lip service is paid to human rights values both within and outside of government. The UK is also an advocate for extending and improving human rights protection internationally.

Current legislation provides a strong legal protection for core civil and political rights via by the interlinked HRA and European Convention on Human Rights mechanisms.
In UK civil society, there is a strong commitment to rights values and activism. Human rights and civil liberties enjoy relatively strong political support, in particular from younger age groups and in the devolved regions.

The UK has a relatively strong institutional framework for protecting rights, which extends beyond the courts - including the Equalities and Human Rights Commission, and the Joint Committee on Human Rights in Parliament (see below).

\section{Current weaknesses}

Little political consensus exists as to the actual substance of human rights guarantees. The existing framework of UK legal rights protection (based on the HRA and European Convention) is vulnerable to political attack, with Conservative calls for a 'British Bill of Rights' to replace them. Judgments by the ECHR in Strasbourg that go against UK policies or impede ministers' executive action capabilities regularly spark public attacks on the Court.

Brexit is removing the safety blanket for certain non-discrimination, migrant and labour rights formerly provided by EU law. The EU's Fundamental Charter of Rights is terminated by the 2018 legislation to withdraw from the EU.

UK governments have been repeatedly able to introduce legislation diluting rights protection, especially in areas like national security, immigration and socio-economic entitlements.

The scope of legal rights protection in the UK is limited. Social and economic rights (for example, to receive appropriate healthcare) are the most poorly established and protected. International human rights law has had a very limited impact on UK law or policy. 


\section{Future opportunities \\ Attempts to reform the existing Convention/ HRA framework led to a pushback that has mobilised political support in favour of retaining them. So far the potential political costs involved, and the inherent difficulties of creating any alterative framework, has meant politicians have not tried to implement major changes from the status quo.}

The divisive nature of Brexit process may actually serve to highlight the importance of legal rights protection.

\section{Future threats}

Human rights remain contested concepts in British political culture, and vulnerable to political attack - especially when the rights of terrorist suspects, migrants, members of unpopular minority groups and other disfavoured social groupings are at issue. For now, the place of legal rights protection within the UK's constitutional culture remains uncertain.

The rise of right-wing populism as a political movement, with its intense anti-immigration focus and proneness to seeking 'naïve statist' solutions, has created a political climate where rights risk being swept away to placate 'nativist' sentiment.

Enthusiasm for human rights values remains very strong among younger age groups: they also continue to attract support from both intellectual opinion-formers and wide swathes of civil society. This bedrock of support could provide a platform for further expansion of existing rights protection in the future, in particular in areas such as socioeconomic rights.

\section{The UK's slow and cautious embrace of human rights}

The UK only became a democracy in a meaningful sense of that term by 1918 with the achievement of universal (male) suffrage after a long process of constitutional struggle. In the previous decades a wide political consensus had emerged to the effect that the Westminster Parliament should exercise its sovereign law-making powers (within the UK mainland itself) in a manner that respected both the rule of law and basic civil liberties. (For obvious reasons, the legal rules applying in the British empire's colonies were treated differently - see Chapter 1.3.) These political constraints, taken together with the limited degree of protection afforded by the common law to personal liberty, helped to give rise to a culture of individual freedom that was comparatively well-developed for its era.

Until the Second World War and even into the post-war period most lawyers shared the complacent view of the turn-of-the-20th-century legal scholar A. V. Dicey that 'the securities for personal freedom are in England as complete as the laws can make them'. He argued:

'In England no man can be made to suffer punishment or to pay damages for any conduct not definitely forbidden by law; every man's legal rights 
or liabilities are almost invariably determined by the ordinary Courts of the realm, and each man's individual rights are far less the result of our constitution than the basis on which that constitution is founded.'

As Anthony Lester has commented, 'the prevailing British constitutional ideology... treated British subjects as "subjects of the Crown" without the benefit of fundamental constitutional rights'. The liberties of the subject were 'residual and negative in their nature'. The individual was free to do anything that the law had not forbidden, but enjoyed no embedded or constitutionally protected positive entitlements that could not be altered by new legislation or the exercise of ministerial prerogative powers. Respect for rights and freedoms in the UK thus depended on Parliament showing restraint when it legislated on matters that affected civil liberties. Even on the political left this stance was accepted by the Labour Party and trade unions. They feared that formally listing human rights would restrict their future ability to legislate in Parliament to achieve social or economic reforms. It might also introduce (conservative) judges as arbiters of what legislation was permissible.

However, as the 20th century progressed, this Diceyan consensus gradually began to be called into question. The parliamentary restraint needed was not always forthcoming. For example, at various periods parliamentary legislation imposed substantial constraints upon civil liberties in areas such as national security and counter-terrorism, trade union activity, and freedom of speech and the press. The wide-ranging discretionary powers enjoyed by public authorities were also prone to abuse, especially when it came to colonial governance in the British empire, and to the treatment of immigrants, minorities and other groups lacking political power even within the home islands.

From the late 1960s on, this 'legacy' state of affairs came under increasing criticism from civil society organisations campaigning in the field of law reform - such as Justice, Charter 88 and Liberty (then called the National Council for Civil Liberties). In Northern Ireland, during the years of the armed conflict between 1969 and 1995, agents of the state were clearly involved in widespread human rights abuses. Taken together with growing concerns about the treatment of ethnic minorities and other vulnerable groups within British society, these developments dealt further blows to any lingering complacency about how liberties and rights were protected within the UK. The rolling back of the UK welfare state that began in the 1980s, combined with the bitter controversies generated by the trade union conflicts of that era, also helped to erode confidence in the status quo.

The political momentum in favour of reform was also amplified by the emergence of the international human rights movement in the wake of the Second World War. As the language of human rights gained in popularity, states committed themselves to respecting an ever-growing range of fundamental rights. Beginning with the European Convention on Human Rights ('the Convention') in 1951, the UK ratified a variety of UN and Council of Europe treaty instruments setting out a range of binding human rights standards. Many of these commitments became the focus of civil society activism, and began to influence policy-making across a range of different fields. However, the ever-increasing salience of 'rights talk' also began to highlight areas where UK law and policy fell well short of established human rights standards. 
In this respect, the civil and political rights set out in the Convention and the interpretation given to these rights by the European Court of Human Rights (ECHR) in Strasbourg became particularly influential. Over time, the Court's jurisprudence established a floor of minimum standards that all European states were expected to respect. And, from the early 1970s on, judgments of the Strasbourg Court began to expose the existence of gaps in human rights protection in UK law. As a consequence, the Court's jurisprudence resulted in significant changes being made to UK law in areas such as freedom of expression, privacy, freedom from discrimination, freedom from inhuman and degrading treatment and the right to fair trial. However, this also drew attention to the lack of a domestic counterpart to the ECHR, and the absence of any legal mechanism within British law which could perform the rights protective function being played by the Strasbourg Court.

The development of the European Union's equality law, as interpreted and applied by the separate Court of Justice of the EU (CJEU), had a similar impact, highlighting the gap that often existed between rhetoric and reality when it came to the UK's commitment to principles of equality, and to non-discrimination more generally. Other areas of human rights law also brought into focus new shortcomings in the UK's track record, in particular when it came to the positive obligations imposed upon the state to take action to protect vulnerable individuals and groups at especial risk of harm - such as children, persons with physical and mental disabilities, refugees and migrants, and the homeless.

All of these factors contributed to fuelling growing disenchantment with the UK's historic approach to human rights issues, and in particular with the lack of any substantial legal human rights protection. In response, British courts began in the early 1990s to identify the existence of a limited set of 'common law rights' such as freedom of expression and the right of access to courts. They now interpreted legislation as subject to a presumption that Parliament did not intend to permit public authorities to violate these common law rights, unless the statutory text contained express or clearly implied provisions to that effect.

However, the major shift in rights thinking was a political one. In 1995 a newly formed (and evanescent) group (the Labour Rights Campaign) circularised Labour constituency parties with a model resolution calling for the incorporation of the European Convention on Human Rights into UK law. This made it onto the final Conference agenda, and was carried overwhelmingly, becoming official Labour policy, and attracting continuing elite support within the party. By 1997, when the Labour Party returned to power after 18 years of being in opposition, the political climate was ripe for reform - which cleared the way for Parliament to enact the Human Rights Act (HRA) in 1998. Piloted through by Lord Irvine (but almost ignored in Tony Blair's autobiography) the Act qualifies as one of the most significant constitutional innovations since the establishment of the UK's modern democratic structures.

\section{The UK's current system of legal rights protection}

The HRA incorporated the key rights set out in the European Convention on Human Rights into UK law and made it possible for individuals to sue public authorities when these rights are violated. It thereby introduced for the first time a comprehensive form of 'rights 
review' into the British legal system. The Act also set out to strike a delicate constitutional balance - by leaving parliamentary sovereignty intact, while making it possible for courts to play an active role in protecting human rights.

A section of the Act [s.6(1) HRA] imposes a duty on all public authorities (aside from Parliament) to act compatibly with Convention rights. If a public authority violates a Convention right, then a court can award the victim of the breach a 'just and appropriate' remedy. The courts nevertheless cannot set aside parliamentary legislation (unlike the case with EU law). This leaves Parliament with the final say when it comes to determining the law as it relates to human rights issues. But the courts are required to interpret primary and secondary legislation under one section [s.3 HRA] 'as far as possible' so as to maintain conformity with Convention rights. Alternatively, where that is not possible, under another section [s.4 HRA] the courts can issue a non-legally binding 'declaration of incompatibility', stating that the legislation in question is incompatible with the Convention. Ministers and Parliament are under no (legal) obligation to respond to such a declaration, beyond the political embarrassment involved. But it was designed to draw Parliament's attention to the existence of a situation of incompatibility with the UK's human rights obligations under the Convention - potentially resulting in a fast-track change of the law, if the politicians agree.

The HRA scheme of rights protection was designed to work with the grain of Britain's constitutional traditions, rather than against it. It preserved parliamentary sovereignty while attempting to ensure that Convention rights will nevertheless 'exert a magnetic force over the entire political and legal system'. Furthermore, since coming into force in 2000, the machinery of the Act has by and large functioned according to its purpose. Its provisions have enhanced awareness of rights in government, while also making it easier for individuals to challenge national laws and practice which infringe their rights.

For example, decisions by the UK courts applying Convention rights in line with the HRA framework have reformed defamation law by extending protection for freedom of speech, enhanced the rights of patients undergoing mental health treatment, granted new rights to unmarried would-be adoptive parents in Northern Ireland, and clarified the rights of persons with serious disabilities. Furthermore, certain major legislative reforms, including the Mental Health Act 2007, the Coroners and Justice Act 2009 and the Protection of Freedoms Act 2012, were passed partially in response to HRA judgments - which had identified problems with the justice and fairness of existing laws.

The legal protection afforded by the HRA has been complemented by other institutional structures. For example, the Westminster Parliament has established a Joint Committee on Human Rights (JCHR), composed of members from both the Commons and the Lords, which scrutinises the human rights impact of legislative proposals and existing law. Outside of Parliament, the official Equality and Human Rights Commission has been established to promote the UK's compliance with human rights and non-discrimination. Furthermore, all the devolved authorities, including the Northern Irish and Welsh Assemblies and the Scottish Parliament, are required to comply with Convention rights by virtue of specific provisions set out in the devolution statutes. This limit on the powers of the devolved authorities reflects the assumption underlying the HRA that Convention rights constitute a floor of legal rights protection that all public authorities should respect: it also demonstrates 
the extent to which rights protection has been woven into the fabric of the UK constitution in the wake of Labour's constitutional reform agenda of the late 1990s.

Other statutes, such as the Freedom of Information Act 2000 and the Equality Act 2010, have also come to play an important role in protecting rights. In particular, the 2010 Act prohibits public authorities from discriminating on the basis of race, sex, disability and a range of other grounds and requires all public authorities to give due regard in the performance of their functions to the need to eliminate discrimination and promote equality of opportunity. The ongoing development of the 'common law rights' jurisprudence by the superior courts has also contributed an additional layer of legal protection, highlighted by the UK Supreme Court's recent finding in R(Unison) $v$ Lord Chancellor that the imposition of employment tribunal fees had breached the common law principle of access to justice.

Outside of the legal context, human rights values attract substantial support - in particular from civil society groups. They also have attracted a certain degree of buy-in from many public authorities, even if the extent of this can vary considerably. UK foreign policy remains committed to promoting respect for the international human rights architecture, and most mainstream UK political voices endorse the importance of rights - in the abstract, at least.

\section{Challenges to the legitimacy of UK human rights protection}

Yet real problems remain with the protection of human rights in the UK. Legal rights protection mechanisms such as the HRA focus on core set of civil and political rights. Other types of human rights - in particular socio-economic rights - lack substantive legal protection, with the majority of the UK Supreme Court confirming in $R$ (SG) $v$ Secretary of State for Work and Pensions that unincorporated human rights treaty instruments do not form part of UK law. In many areas - in particular the spheres of immigration control, national security/counter-terrorism, freedom of association and speech, and the treatment of persons with mental disabilities and other vulnerable groups - UK law has been the frequent subject of criticism from human rights expert committees at the UN and the Council of Europe.

Furthermore, the manner in which the ECHR and HRA serve as the keystones of the current British system of legal rights protection has come under sustained political attack (from the right or conservative forces) over the last few years. A right-wing press narrative has developed that portrays human rights adjudication as 'fetishising' or being excessively concerned with the rights of minorities at the expense of the public interest. The Hirst (No. 2) decision of the European Court of Human Rights in Strasbourg on prisoner voting rights attracted considerable political hostility, as have judgments by the EU and UK courts which have imposed constraints on the power of ministers to deport non-nationals. Calls have been made for a fundamental re-think of the UK's relationship with the Strasbourg Court, and by extension with the Convention/HRA scheme of rights protection more generally. For example, Lord Hoffmann in 2009 suggested that an international court like Strasbourg lacked the 'constitutional legitimacy' to impose its interpretation of the abstract rights set out in the text of the Convention on national parliaments and courts, and attacked what he saw as expansionist tendencies within the jurisprudence of the Court. Leading 
politicians and conservative think tanks have voiced similar views, expressing concern in particular that the HRA and ECHR unduly extended judicial power at the expense of political decision-making.

In turn, there has been a pushback against many of these claims. NGOs, academic commentators and political figures (even liberal Conservatives) have defended the HRA and the Strasbourg Court's jurisprudence. They argue that its 'living instrument' interpretative approach allows the Court to maintain the integrity of its case law by ensuring that it reflects contemporary moral and social understandings of the core content of human rights. The argument has also been made that the UK's membership of the ECHR has been a positive force for good, helping to enhance respect for human rights and providing an important safeguarding function in the context of Northern Ireland. Supporters of the legal status quo also make the case that the ECHR link and the provisions of the HRA is wholly compatible with the UK's constitutional values, including the principle of democratic selfgovernance as reflected in the doctrine of parliamentary sovereignty.

Despite this, critics of the HRA continue to argue that radical reform is needed. Important elements of the Conservative Party in particular support repeal of the HRA and its replacement by a 'British Bull of Rights', which would reduce the influence of Strasbourg on UK law and limit the existing scope of judicial protection of rights in areas such as national security and immigration control. The Prime Minister, Theresa May, has even suggested that serious consideration should be given to the UK leaving the European Convention system of rights protection.

However, formidable political obstacles lie in the way of any such radical reform. The devolved governments remain very hostile to any tinkering with the HRA, which would require adjustments to be made to devolved governance arrangements - and, in the case of Northern Ireland, might breach the terms of the Belfast Agreement 1998. Any move on the part of the UK to withdraw from the ECHR is likely to meet stiff diplomatic resistance from other European governments. Furthermore, any attempt to repeal the HRA is likely to generate substantial legal uncertainty, and to trigger considerable political push-back within the UK.

All of these factors mean that Conservative Party ambitions at various times and in varying strengths to amend/repeal the HRA have thus far not been translated into concrete legislative proposals. However, it remains to be seen how this situation will play out in the future. Brexit is already reshaping important elements of rights protection in the UK. The EU (Withdrawal) Act 2018 gives sweeping powers to the UK government to amend or repeal existing legislation/regulations which give effect to EU law. Many observers fear that these powers could be used in the future to undermine the protection currently afforded by EU law in areas such as equality law, labour law and migrant rights. Furthermore, the international climate has grown much more hostile to human rights values more generally, with the rise of aggressive populism (especially nationalist-based) and majoritarian/antimigrant perspectives in many different states. These trends also surface regularly in British political debates, making the future of human rights protection in the UK look very uncertain. 


\section{Conclusions}

Once established on the statute books bills or charters of rights have mostly tended to become more and more embedded over time in the thinking and operations of the countries involved. The longer that they can endure and operate, the more difficult it becomes for their critics or opponents to abolish or replace them. The inaction so far on earlier Tory pledges of a 'British Bill of Rights' instead of the HRA since 2010 might be evidence of such an effect. And the bedrock of support for human rights amongst younger age groups, intellectual opinion-formers and wide swathes of civil society could yet provide a platform for further expansion of existing rights protection in the future, in particular in areas such as socio-economic rights where the UK currently falls short. This is also the area highlighted most by the Brexit process, with its polarising impacts on UK society. Potentially, then, repeal of the HRA or withdrawal from the ECHR may fall off the political agenda. In fact, the Brexit process may actually serve to highlight the importance of legal rights protection, and to strengthen support for the status quo accordingly.

However, human rights law and concepts remain vulnerable to political attack - especially when they seem to protect anti-social minorities like terrorist suspects, or unpopular minority groups, like migrants. Right-wing populist political movements, and some sections of the press, with their intense anti-immigration focus, have created a political climate where rights risk being swept away to placate nativist sentiment. For now, the place of legal rights protection within the UK's constitutional culture remains uncertain. Much may depend upon the political fall-out from EU withdrawal, and how UK society responds to the current crisis of neo-liberalism.

Colm O'Cinneide is Professor of Constitutional and Human Rights Law at UCL. 